\title{
Low Pressure Gas Electron Diffraction: an Experimental Setup and Case Studies
}

\author{
Yury V. Vishnevskiy ${ }^{* \dagger} \quad$ Sebastian Blomeyer ${ }^{\dagger} \quad$ Christian G. Reuter $^{\dagger}$
}

\section{Abstract}

Principles of low pressure gas electron diffraction (LPGED) are introduced. An experimental setup has been constructed for measuring electron diffraction patterns of gaseous samples at pressures below $10^{-3}$ mbar. Test measurements have been performed for benzoic acid at $T=287 \mathrm{~K}$ corresponding to a vapor pressure of the substance $P=2 \times 10^{-4}$ mbar, for iodoform $\mathrm{CHI}_{3}$ at $T=288 \mathrm{~K}\left(P=4 \times 10^{-4}\right.$ mbar) and for carbon tetraiodide $\mathrm{CI}_{4}$ at $T=290$ $\mathrm{K}\left(P=1 \times 10^{-4} \mathrm{mbar}\right)$. Due to the low experimental temperature thermal decomposition of $\mathrm{CI}_{4}$ has been prevented, which was unavoidable in previous classical measurements at higher temperatures. From the obtained data the molecular structures have been successfully refined. The most important semi-empirical equilibrium molecular parameters are $r_{\mathrm{e}}\left(\mathrm{C}_{\mathrm{ar}}-\mathrm{C}_{\mathrm{ar}}\right)_{\mathrm{av}}=1.387(5) \AA$ in benzoic acid, $r_{\mathrm{e}}(\mathrm{C}-\mathrm{I})$ $=2.123(3) \AA$ in iodoform and $r_{\mathrm{e}}(\mathrm{C}-\mathrm{I})=2.133(7) \AA$ in carbon tetraiodide. The determined parameters showed consistency with theoretically predicted values. A critical comparison with results of the earlier investigations has also been done.

\section{Introduction}

One of the major sources of experimental data for structures of free molecules is gas electron diffraction (hereafter GED). Using this technique numerous compounds from different classes have been investi-

\footnotetext{
*corresponding author, yury.vishnevskiy@uni-bielefeld.de

${ }^{\dagger}$ Lehrstuhl für Anorganische Chemie und Strukturchemie, Universität Bielefeld, Universitätsstrasse 25, 33615 Bielefeld, Germany. Tel.: +49521106 6164 Fax: +49521 1066026
}

gated, including famous buckminsterfullerene $\mathrm{C}_{60}[1]$ ferrocene $\mathrm{Fe}\left(\mathrm{C}_{5} \mathrm{H}_{5}\right)_{2}[2]$, metalloporphyrins [3] and many others [4]. For a recent brief overview of the GED method the reader is referred to the respective chapters by István and Magdolna Hargittai in Encyclopedia of Spectroscopy and Spectrometry $[5,6]$. In principle, this method is suitable for studying any substance, which can be evaporated. The question is, whether the pressure of its vapor is high enough for producing diffraction of electrons with sufficient intensity. Figure 1 shows the scheme of a typical GED experiment. For a given compound the total intensity of diffracted electrons is proportional to the product of the number of molecules and the number of incident electrons in the diffraction point per unit time. Accordingly, there are three distinct parameters of the GED experiment, which can be adjusted in order to measure diffraction patterns successfully: (a) the pressure $P$ of the vapor of the investigated substance, (b) the current $I$ in the primary electron beam and (c) the exposure time $t$. Their product is proportional to the level of signal $S$ measured on the detector:

$$
S \propto P \times I \times t
$$

Accumulated over last decades experience shows that all of these parameters have particular ranges of optimal values [7]. The exposure time $t$ can be several seconds up to a few minutes. Shorter exposures are preferable to ensure the stability of conditions during measurements and to reduce the consumption of the sample, which can be sometimes very valuable. Optimal values for the electron current $I$ are usually in the range $0.1-5 \mu \mathrm{A}$. Larger values can cause instabilities in the electron optics and increase levels of continuous X-rays, coming from apertures and the 
electron beam trap. To reduce the background intensity the diffraction chamber must be kept under high vacuum, typically $10^{-6}$ mbar or better. Therefore inlet systems are constructed so that the sample is introduced into the diffraction point with a reasonably low pressure and then immediately pumped out and collected on surfaces of the cold trap. In classical GED experiments the pressure of the substance vapor must be in the range about $0.1-10$ mbar. Adjustable valves can be used for the reduction of the pressure if the substance is too volatile. In case of low volatility the substance is heated to achieve the required vapor pressure. Technically this is a more complicated problem, which has been solved by constructing different evaporators for measurements at middle [8], high $[9,10]$ and very high temperatures up to $2300 \mathrm{~K}$ [11] and even up to about $3300 \mathrm{~K}$ [12]. Still, numerous compounds could not be studied due to thermal decomposition at elevated temperatures. In exceptionally simple cases products of decomposition can be taken into account in the analysis of data. For example this was done in a study of carbon tetraiodide [13] resulting in a refined C-I bond length with relatively large uncertainty $r_{\mathrm{g}}=2.157(10) \AA$. In spite of the very detailed analysis of the data the authors of this investigation write that "the rest of the results of our ED study are not unambiguous" [13]. In general case thermally labile substances should be investigated at low temperatures to avoid decomposition. However, the corresponding vapor pressure would be too low for the classical GED experiment. A workaround to this problem has been suggested earlier by increasing the electron current in the primary beam [14]. Also, based on ideas of molecular beams an evaporator of a special donut form has been proposed [15]. Nevertheless currently there are no experimental GED setups suitable for measurements at low vapor pressures.

At Bielefeld University we are constantly developing our KD-G2 gas electron diffractometer [8]. Recently we have published a paper [16] with details on the most principal improvements facilitated the current work. In this contribution we describe principles and the construction of our new evaporator for low pressure gas electron diffraction (LPGED) and results of several test measurements.

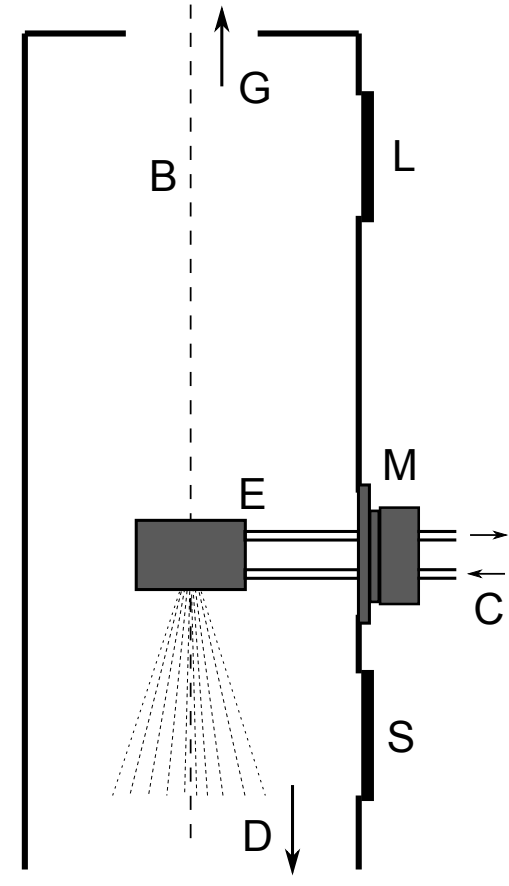

Figure 1: Scheme of the diffraction camera in the GED instrument. B is the primary electron beam; $\mathrm{E}$ is the evaporator combined with the cold trap; C connections for cooling liquid; D and G show the directions to the detector and the electron gun, respectively; L, M and S show the possible positions of the evaporator corresponding to the long, middle and short distances to the detector, respectively.

\section{Experiment}

The developed setup is based on the available diffractometer [16]. The general scheme of our GED experiment is depicted in Figure 1. Briefly, the primary electron beam is introduced into the evacuated diffraction chamber, interacts with molecules of the sample in the evaporator and the scattered electrons are collected on the detector.

\section{$3.1 \quad$ Evaporator}

A major part of our work has been devoted to the construction of the evaporator. Its model has been 


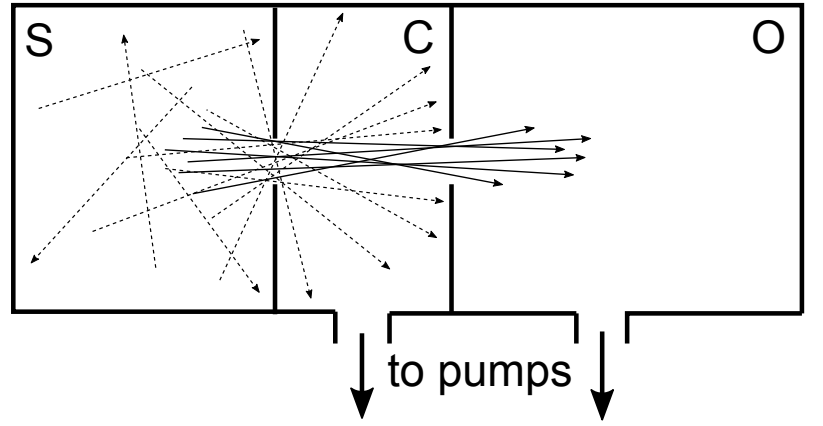

Figure 2: Classical scheme of the formation of the molecular beam. S, C and O are the source, collimating and observation chambers, respectively. Arrows show trajectories of molecules. Solid arrows correspond to molecules forming the molecular beam.

built on principles of molecular beams [17]. The basic idea is shown in Figure 2. A sample (most usually in the solid state) is placed in the source chamber. The mean free path (i.e., the travelling distance without collisions) $l$ for molecules in its vapor can be calculated as

$$
l=\frac{k_{\mathrm{B}} T}{\sqrt{2} \pi d^{2} P}
$$

where $k_{\mathrm{B}}$ is the Boltzmann's constant, $T$ is the absolute temperature, $d$ is the kinetic diameter of the molecule, $P$ is the vapor pressure. The diameter $d$ (in $\AA$ ) can be calculated from viscosity $\eta$ (in micropoise) as

$$
d=1.6339 \frac{(M T)^{1 / 4}}{\eta^{1 / 2}}
$$

where $M$ is the molecular weight $\left(\mathrm{g} \mathrm{mol}^{-1}\right)$ and $T$ is the temperature in Kelvin. From the source chamber the molecules can enter the collimating chamber at different angles and then can be pumped out or pass further to the observation chamber. For the formation of the molecular beam (i.e., a collimated flow of molecules) in the observation chamber the mean free path $l$ must be significantly larger than the linear dimensions of the orifices and the distance between them. Developing this principle further an evaporator with a cell in donut form has been designed, see Figure 3. In contrast to one-dimensional molecular beams this ring-shaped construction should provide

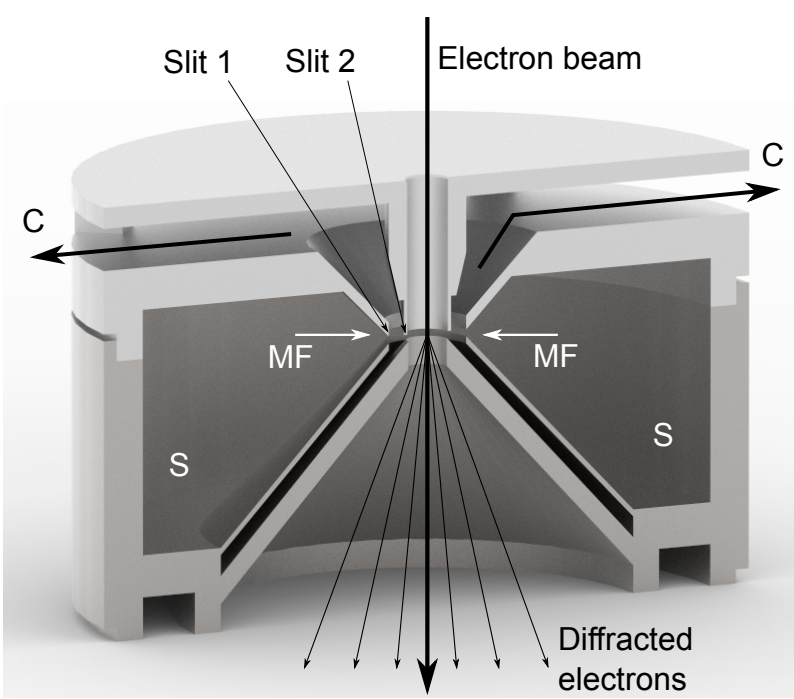

Figure 3: A cut of the CAD model of the cell in the evaporator. $\mathrm{S}$ is the source chamber, $\mathrm{C}$ indicate directions to the cold trap; MF indicate directions for formation of the gas molecular film.

conditions for two-dimensional gas molecular films. In this case a part of molecules is returning back to the sample chamber after passing the diffraction volume. In turn, this should lower the sample consumption and reduce the overall background pressure in the diffraction chamber. Particular dimensions of the central part of the cell around the diffraction point have been determined from the following considerations. High electron currents lead to increased diameters of the primary electron beam. Our estimations for the largest values of the beam diameter were about 1-2 $\mathrm{mm}$ in the diffraction volume. For comparison, the observed earlier diameter of the electron beam in our setup was $0.35 \mathrm{~mm}$ at a current of $1 \mu \mathrm{A}$ [16]. Accordingly, in the construction the inner diameter of the channel for the primary electron beam was $3 \mathrm{~mm}$. For determining the optimal configuration of the circular slits we have done a series of calculations of the mean free path $l$ at different conditions (see Table S1 in Supplementary Material) using equation 2. For small and middle-sized molecules with $d \leq 10 \AA$ the mean free path $l$ is at least $9 \mathrm{~mm}$ at 


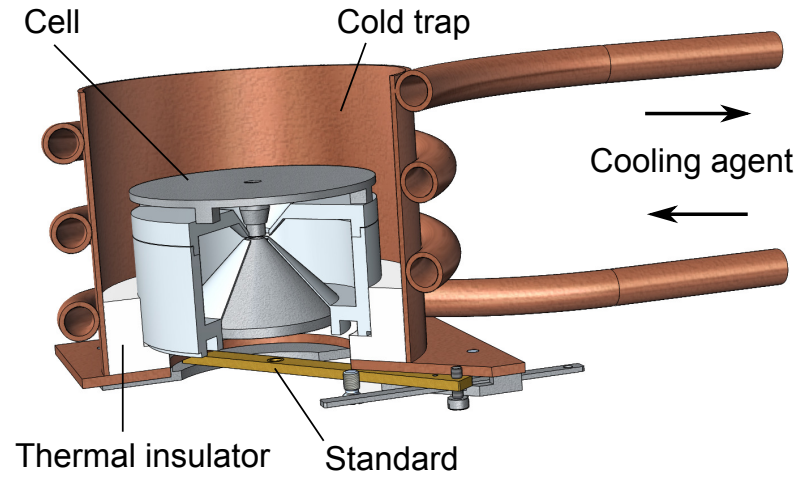

Figure 4: A cut of the CAD model of the evaporator head.

$T=300 \mathrm{~K}$ and $P=10^{-3}$ mbar. At the same temperature larger molecules require lower pressure values to achieve comparable $l$ values. For example, molecules with $d=20 \AA$ have $l=23 \mathrm{~mm}$ at $T=300 \mathrm{~K}$ and $P=10^{-4}$ mbar. Note, the mean free path $l$ increases when the temperature $T$ rises, as Eq. 2 shows (particular values are collected in Table S1). Accordingly, the cell has been constructed so that it is operational at least in the stated conditions and also at elevated temperatures. The opening of the slits (the vertical distance) was $1 \mathrm{~mm}$ and the distance (horizontal) between slits was $1.5 \mathrm{~mm}$ (see Figure 3), which is significantly less than the expected magnitudes of the mean free path.

The cell is placed in the head of the evaporator (see Figure 4), which is essentially a cold trap for collecting surplus of the sample coming from the cell. Additionally, on the bottom of the head a holder for the standard for wavelength calibration is mounted, which can be mechanically placed into electron beam position. As a standard in this work we used polycristalline zinc oxide $\mathrm{ZnO}$ manually evaporated onto a TEM net made of copper. Figure 5 shows the model of the complete evaporator equipped with a reservoir for liquid nitrogen used as a cooling agent. Alternatively, the reservoir can be detached and tubes for an operation with cooling liquid can be connected directly to the evaporator. The position of the cell in the head with respect to the electron beam can be

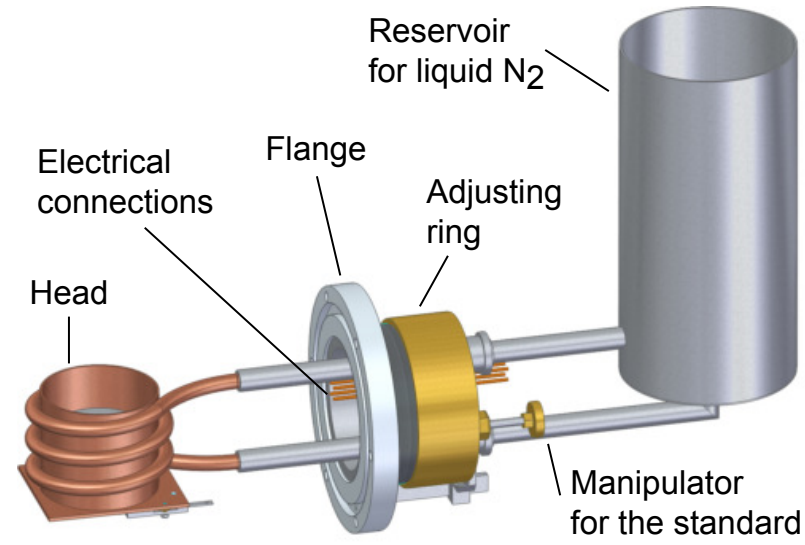

Figure 5: The CAD model of the complete evaporator.

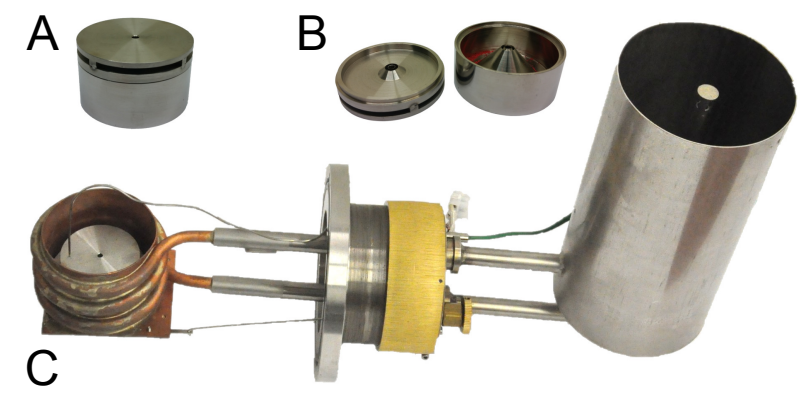

Figure 6: The first prototype of the evaporator. The cell is also shown separately in closed (A) and opened (B) state. $\mathrm{C}$ is the complete evaporator with the installed cell inside.

controlled with the adjusting ring. The head can be pushed and pulled by rotating this ring. In the first prototype constructed in our local mechanical workshop (see Figure 6) the cell was made from stainless steel and the head was from copper. The adjusting ring and the outer part of the manipulator for the standard were made from brass, the rest of the evaporator was from stainless steel. This evaporator was initially built for experiments without heating of samples. Below we demonstrate some results obtained with this setup. 
Table 1: Parameters of LPGED (this work) and GED experiments. ${ }^{\mathrm{a}}$

\begin{tabular}{|c|c|c|c|c|c|c|}
\hline \multirow[b]{2}{*}{ Parameter } & \multicolumn{2}{|c|}{$\mathrm{C}_{6} \mathrm{H}_{5} \mathrm{COOH}$} & \multicolumn{2}{|c|}{$\mathrm{CHI}_{3}$} & \multicolumn{2}{|c|}{$\mathrm{CI}_{4}$} \\
\hline & LPGED & GED [18] $]^{\mathrm{b}}$ & LPGED & GED [19] & LPGED & GED $[13]^{b}$ \\
\hline$L^{\mathrm{c}}, \mathrm{mm}$ & 243.0 & $243.9,494.4$ & 243.0 & 244.5 & 243.0 & 190,500 \\
\hline$V_{\mathrm{ED}}{ }^{\mathrm{d}}, \mathrm{kV}$ & 60 & 42 & 60 & 37 & 60 & 60 \\
\hline$I_{\mathrm{ED}}{ }^{\mathrm{e}}, \mu \mathrm{A}$ & 10.8 & n.i. & 0.9 & 1.5 & $4.5-5.1$ & n.i. \\
\hline$P_{\text {res }}{ }^{\mathrm{f}}, \mathrm{mbar}$ & $1 \times 10^{-6}$ & n.i. & $4 \times 10^{-7}$ & $2 \times 10^{-6}$ & $3 \times 10^{-7}$ & n.i. \\
\hline$T^{\mathrm{g}}, \mathrm{K}$ & $287-289$ & 408,403 & 289 & 395 & 290 & 396 \\
\hline$P_{\text {sub }}{ }^{\mathrm{h}}, \mathrm{mbar}$ & $2 \times 10^{-4}$ & 18,13 & $4 \times 10^{-4}$ & 1.1 & $1 \times 10^{-4}$ & 1.2 \\
\hline$d^{\mathrm{i}}, \AA$ & 9.00 & $8.27,8.30$ & 8.39 & 7.79 & 9.73 & 9.04 \\
\hline$l^{\mathrm{j}}, \mathrm{mm}$ & 55 & $\begin{array}{l}1.0 \times 10^{-3} \\
1.4 \times 10^{-3}\end{array}$ & 32 & $1.9 \times 10^{-2}$ & 95 & $1.3 \times 10^{-2}$ \\
\hline$t^{\mathrm{k}}, \sec$ & $30-60$ & n.i. & $40-90$ & $110-140$ & $20-60$ & n.i. \\
\hline$s^{1}, \AA^{-1}$ & $4.4-30.8$ & $\begin{array}{l}8.0-29.0 \\
3.0-14.0\end{array}$ & $4.6-25.9$ & $4.5-33.8$ & $4.4-25.0$ & $\begin{array}{l}8.00-31.75 \\
2.00-14.00\end{array}$ \\
\hline$\Delta s^{\mathrm{m}}, \AA^{-1}$ & 0.2 & 0.25 & 0.2 & n.i. & 0.2 & $0.25,0.125$ \\
\hline$\lambda^{\mathrm{n}}, \AA$ & $0.04903(17)$ & 0.058378 & $0.04925(16)$ & 0.06329 & $0.04913(13)$ & n.i. \\
\hline$w R_{\exp }{ }^{\circ}, \%$ & 2.41 & n.i. & 5.34 & n.i. & 8.16 & n.i. \\
\hline$w R_{\text {str }} \mathrm{p}, \%$ & 2.52 & n.i. & 8.07 & n.i. & 6.93 & 5.44 \\
\hline
\end{tabular}

${ }^{\mathrm{a}}$ n.i. stands for not indicated in cited paper. ${ }^{\mathrm{b}}$ Parameters for two series of experiments are given; common values are not duplicated. ${ }^{\mathrm{c}}$ Distance from diffraction point to detector. ${ }^{\mathrm{d}}$ Accelerating voltage for primary electron beam. ${ }^{\text {e }}$ Current in primary electron beam. ${ }^{\mathrm{f}}$ Residual pressure in diffraction chamber during exposure. ${ }^{\mathrm{g}}$ Temperature of substance in diffraction point. ${ }^{\mathrm{h}}$ Pressure of substance at experimental temperature; the values were calculated from data in refs. [20] for benzoic acid, [21] for $\mathrm{CHI}_{3}$ and [22] for $\mathrm{CI}_{4} \cdot{ }^{\mathrm{i}}$ Kinetic diameter of molecule calculated using Eq. 3 from viscosity data [23]. ${ }^{\mathrm{j}}$ Calculated mean free path according to Eq. 2. ${ }^{\mathrm{k}}$ Exposure time. ${ }^{\mathrm{l}}$ Covered in measurement and processed range of $s .{ }^{\mathrm{m}}$ Step size for $s .{ }^{\mathrm{n}}$ Electron wavelength. ${ }^{\mathrm{o}}$ Weighted experimental $R$-factor [24] for $s M(s) .{ }^{\mathrm{P}}$ Weighted structural $R$-factor for $s M(s)$ calculated as $\left[\sum w_{i}\left\{s_{i} M\left(s_{i}\right)_{\text {model }}-s_{i} M\left(s_{i}\right)_{\text {exper }}\right\}^{2} / \sum w_{i}\left\{s_{i} M\left(s_{i}\right)_{\text {exper }}\right\}^{2}\right]^{1 / 2} \times 100 \%$

\subsection{Measurements}

The constructed evaporator was installed in the KDG2 gas electron diffractometer [8] at Bielefeld University. Commercial (Sigma-Aldrich) samples of benzoic acid (purity $\geq 99.9 \%$ ), iodoform $(99 \%$ ) and carbon tetraiodide $(97 \%)$ were used without further purification. Electron diffraction patterns of the samples were measured in three separate experiments without heating. Liquid nitrogen was used as cooling agent. In all cases the evaporator was installed in the middle position with respect to the detector level (see Figure 1). BAS-MP Imaging Plates (IP) were used as detectors for measuring intensities of diffracted elec- trons. Exposed IPs were scanned using a calibrated Fuji BAS-1800II reader in the 16-bit mode with the spatial resolution $0.05 \mathrm{~mm}$ per pixel. Digitized images have been converted into total intensity functions as usually [25]. In each experiment diffraction patterns of $\mathrm{ZnO}$ were also recorded and used for calibration of electron wavelengths. As the reference values for the lattice constants of $\mathrm{ZnO}$ were used $a=$ $3.2495 \AA$ and $c=5.2069 \AA[26]$. The most important parameters of the experiments are collected in Table 1. 

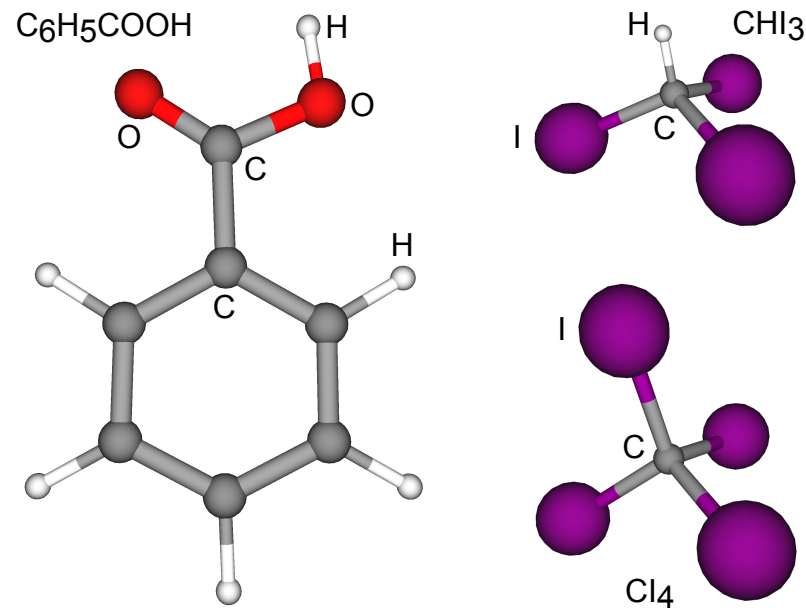

Figure 7: Molecular structures of benzoic acid $\left(\mathrm{C}_{6} \mathrm{H}_{5} \mathrm{COOH}\right)$, iodoform $\left(\mathrm{CHI}_{3}\right)$ and carbon tetraiodide $\left(\mathrm{CI}_{4}\right)$. Labels of some atoms are omitted for clarity.

\subsection{Structural refinements}

First, supplementary quantum-chemical calculations were performed for all three molecules (see Figure 7 for their structures). For benzoic acid the optimized equilibrium structure was computed at the ae$\operatorname{CCSD}(\mathrm{T}) /$ cc-pwCVTZ level of theory [27, 28]. Parameters of this structure were used as starting and regularizing values in the refinement procedure [29]. Analytical harmonic and numerical cubic force fields were calculated at the DFT B3LYP/def2-TZVP level [30-32]. Theoretical equilibrium structures of $\mathrm{CHI}_{3}$ and $\mathrm{CI}_{4}$ were also calculated using the ae- $\operatorname{CCSD}(\mathrm{T})$ method paired with basis sets cc-pwCVnZ-PP $(n=$ D, T and Q) with small-core ECP28MDF pseudopotential [33] for iodine atoms. From these data complete basis set structures were computed by fitting the parameters of the equation $r=r_{\mathrm{CBS}}+A e^{-n B}$, where $r_{\mathrm{CBS}}, A, B$ are adjustable parameters and $n$ is the cardinal number $(n=2(\mathrm{D}), 3(\mathrm{~T}), 4(\mathrm{Q}))$ of the respective basis set. Force fields for these two molecules were calculated using the second order Møller-Plesset perturbation theory MP2 [34] in frozen-core variant with SDB-cc-pVTZ basis set [35]. All DFT and MP2 calculations were done using the Gaussian16 [36] pro-

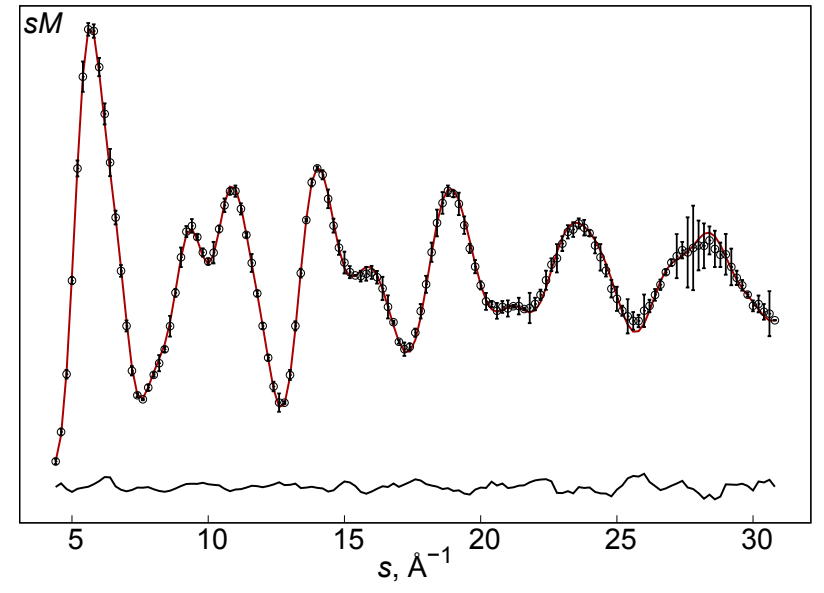

Figure 8: Experimental (circles) and model (line) molecular intensity $s M(s)$ functions of benzoic acid. Below is the difference curve. Error bars for the experimental data are threefold standard deviations.

gram package. Coupled cluster calculations were performed using the Cfour [37] programs. The force fields were used further for computing interatomic vibrational amplitudes and corrections $\left(r_{\mathrm{e}}-r_{\mathrm{a}}\right)$ employing the VibModule program [38]. The structures have been refined using the UNEX program [39], for details see Supplementary Material. Background elimination procedure has been applied to reduced intensity functions (see Figures S2-S4) according to the method described earlier [40]. Experimental $s M(s)$ functions were averaged and individual standard deviations were calculated for all data points (see Figures 8, 9 and 10). Standard deviations for the refined parameters were calculated using Monte-Carlo method [41] taking into account uncertainties in experimental $s M(s)$ intensities and electron wavelengths. Most important theoretical and refined parameters are collected in Tables 2, 3 and 4. Radial distribution functions are shown in Figures 11, 12 and 13. 
Table 2: Selected parameters of benzoic acid. ${ }^{\mathrm{a}}$

\begin{tabular}{|c|c|c|c|c|}
\hline \multirow[b]{2}{*}{ Parameter } & Theoretical $^{b}$ & \multicolumn{3}{|c|}{ Experimental } \\
\hline & CC, DFT $r_{\mathrm{e}}$ & This work $r_{\mathrm{e}}$ & This work $r_{\mathrm{a}}$ & Ref. [18] $r_{\mathrm{a}}$ \\
\hline$r\left(\mathrm{C}_{\mathrm{ar}}-\mathrm{C}_{\mathrm{ar}}\right)_{\mathrm{av}}{ }^{\mathrm{c}}$ & 1.393 & $1.387(5)$ & $1.393(5)$ & $1.401(2)$ \\
\hline$r\left(\mathrm{C}_{\mathrm{ar}}-\mathrm{COOH}\right)$ & 1.485 & $1.485(4)$ & $1.493(4)$ & $1.484(6)$ \\
\hline$r(\mathrm{C}-\mathrm{O})$ & 1.352 & $1.342(4)$ & $1.350(4)$ & $1.367(8)$ \\
\hline$r(\mathrm{C}=\mathrm{O})$ & 1.207 & $1.202(4)$ & $1.205(4)$ & $1.225(6)$ \\
\hline$r\left(\mathrm{C}_{\mathrm{ar}}-\mathrm{H}\right)_{\mathrm{av}}{ }^{\mathrm{c}}$ & 1.081 & $1.088(4)$ & 1.103(4) & $1.102(8)$ \\
\hline$l\left(\mathrm{C}_{\mathrm{ar}}-\mathrm{C}_{\mathrm{ar}}\right)_{\mathrm{av}}{ }^{\mathrm{c}}$ & 0.045 & \multicolumn{2}{|c|}{$0.051(1)$} & $0.054(6)$ \\
\hline
\end{tabular}

${ }^{a}$ Bond lengths $r$ and amplitudes $l$ in $\AA$, uncertainties in parentheses are $1 \sigma$ errors.

b ae-CCSD(T)/cc-pwCVTZ for geometrical parameters, B3LYP/def2-TZVP for amplitudes. ${ }^{\mathrm{c}}$ Average value for benzene ring.

Table 3: Parameters of iodoform. ${ }^{\text {a }}$

\begin{tabular}{|c|c|c|c|c|}
\hline \multirow[b]{2}{*}{ Parameter } & \multirow{2}{*}{$\begin{array}{l}\text { Theoretical }^{\mathrm{b}} \\
\text { CC, MP2 } r_{\mathrm{e}}\end{array}$} & \multicolumn{3}{|c|}{ Experimental } \\
\hline & & This work $r_{\mathrm{e}}$ & This work $r_{\mathrm{g}}$ & Ref. [19] $r_{\mathrm{g}}$ \\
\hline$r(\mathrm{C}-\mathrm{H})$ & 1.081 & $1.081^{\mathrm{c}}$ & $1.102^{\mathrm{c}}$ & $1.111^{\mathrm{c}}$ \\
\hline$r(\mathrm{C}-\mathrm{I})$ & 2.127 & $2.123(3)$ & $2.133(3)$ & $2.145(3)$ \\
\hline$r(\mathrm{I} \cdots \mathrm{I})$ & 3.533 & $3.528(11)$ & $3.541(11)$ & $3.549(1)$ \\
\hline$\angle(\mathrm{H}-\mathrm{C}-\mathrm{I})$ & 106.4 & $106.3(5)$ & & $107.0(2)^{\mathrm{d}}$ \\
\hline$\angle(\mathrm{I}-\mathrm{C}-\mathrm{I})$ & 112.3 & $112.4(4)$ & & $111.9(2)^{\mathrm{d}}$ \\
\hline$l(\mathrm{C}-\mathrm{I})$ & 0.055 & & $0(7)$ & $0.067(2)$ \\
\hline$l(\mathrm{I} \cdots \mathrm{I})$ & 0.083 & & $3(1)$ & $0.108(1)$ \\
\hline
\end{tabular}

${ }^{\text {a }}$ Distances $r$ and amplitudes $l$ in $\AA$, angles in degrees, uncertainties in parentheses are $1 \sigma$ errors. ${ }^{\mathrm{b}}$ For geometrical parameters ae-CCSD(T)/CBS, for amplitudes fc-MP2/SDB-cc-pVTZ. ${ }^{\mathrm{c}}$ Assumed. ${ }^{\mathrm{d}}$ Angles in ref. [19] are given in terms of $r_{\alpha}$ structure.

\section{Discussion}

Some individual ideas lying in the basis of the described experimental setup are not entirely new. Molecular beams were already used in electron diffraction earlier [42, 43], although in these measurements sample pressures were significantly higher. Also at least one test low-pressure-high-current experiment was performed [14] and a donut-shaped cell was suggested by Ivanov [15]. Nevertheless, the data on these topics in application to electron diffraction are extremely scarce. In fact our setup is currently the only one available in the world for LPGED measurements. Benzoic acid, iodoform and carbon tetraiodide have been already studied by GED method [13, 18, 19], which makes them suitable for testing purposes. The particular reason for choosing these compounds was (a) each of them was studied relatively recently and represent the modern state of classical GED experiments; (b) the published data were measured in different laboratories using different experimental setups, which makes the comparison with our results more meaningful.

In Table 1 we have collected LPGED experimental conditions from this work with corresponding parameters of the earlier classical GED experiments. The most important systematic difference is that in LPGED significantly lower sample vapor pressures 
Table 4: Parameters of carbon tetraiodide. ${ }^{\text {a }}$

\begin{tabular}{|c|c|c|c|c|}
\hline \multirow[b]{2}{*}{ Parameter } & Theoretical $^{\mathrm{b}}$ & \multicolumn{3}{|c|}{ Experimental } \\
\hline & CC, MP2 $r_{\mathrm{e}}$ & This work $r_{\mathrm{e}}$ & This work $r_{\mathrm{g}}$ & Ref. [13] $r_{\mathrm{g}}$ \\
\hline$r(\mathrm{C}-\mathrm{I})$ & 2.145 & $2.133(7)$ & $2.143(7)$ & $2.157(10)$ \\
\hline$r(\mathrm{I} \cdots \mathrm{I})$ & 3.503 & $3.484(12)$ & $3.497(12)$ & $3.530(7)$ \\
\hline$l(\mathrm{C}-\mathrm{I})$ & 0.057 & \multicolumn{2}{|c|}{$0.058(12)$} & $0.063^{\mathrm{c}}$ \\
\hline$l(\mathrm{I} \cdots \mathrm{I})$ & 0.083 & \multicolumn{2}{|c|}{$0.108(1)$} & $0.106(23)$ \\
\hline
\end{tabular}

${ }^{a}$ Distances $r$ and amplitudes $l$ in $\AA$, uncertainties in parentheses are $1 \sigma$ errors in this work and estimated total errors from ref. [13]. ${ }^{\mathrm{b}}$ For distances ae-CCSD(T)/CBS, for amplitudes fc-MP2/SDB-cc-pVTZ levels of theory. ${ }^{\mathrm{c}}$ Assumed.

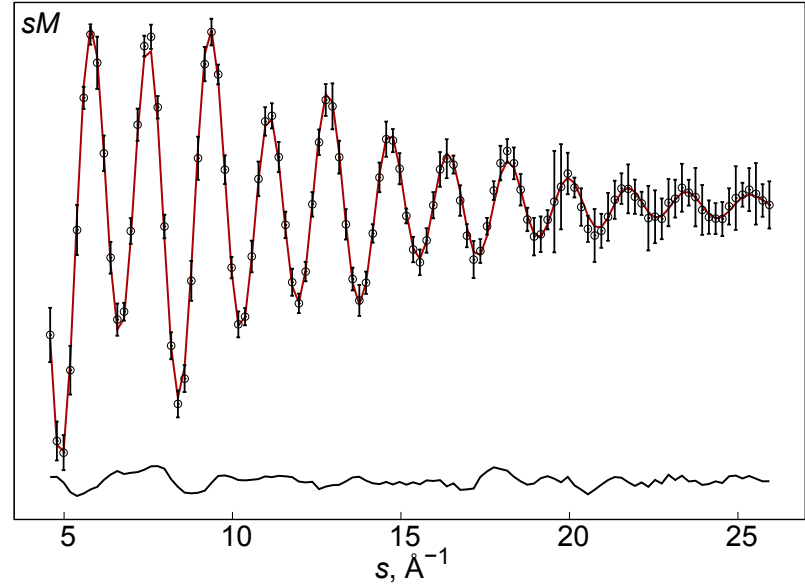

Figure 9: Experimental (circles) and model (line) molecular intensity $s M(s)$ functions of iodoform. Below is the difference curve. Error bars for the experimental data are threefold standard deviations.

were used and no heating was required, as opposed to the GED experiments. In turn, the mean free paths $l$ in LPGED were several orders of magnitude longer. However, from our experience this typically requires higher currents in the electron beam, like it was for benzoic acid with relatively weak scattering ability in comparison to the other two molecules. The exception here was iodoform, for which electron diffraction patterns were successfully measured even at 0.9 $\mu \mathrm{A}$. In LPGED we needed longer exposures up to 90 seconds for recording patterns with optimal sig-

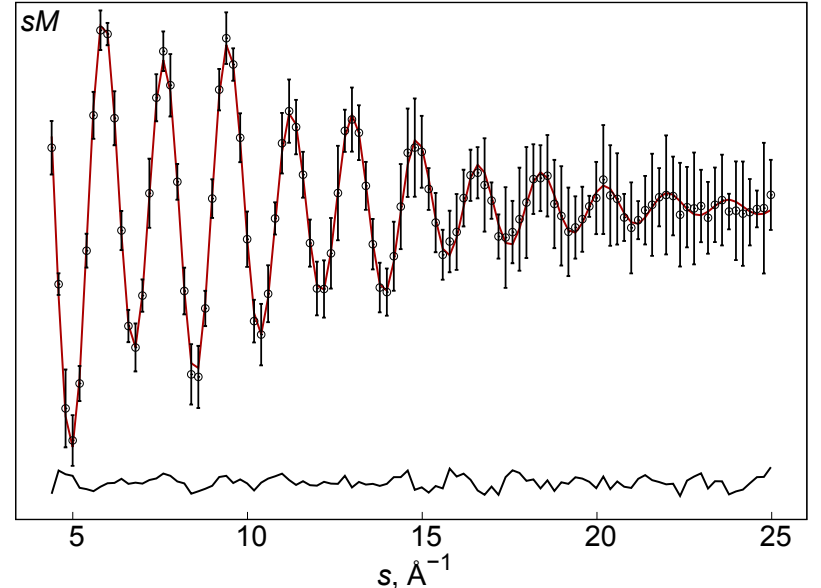

Figure 10: Experimental (circles) and model (line) molecular intensity $s M(s)$ functions of carbon tetraiodide. Below is the difference curve. Error bars for the experimental data are threefold standard deviations.

nal to noise ratio. For comparison, in classical GED measurements with our setup typical exposure times are about 10 seconds $[16,40]$. In earlier investigations, like for $\mathrm{CHI}_{3}$ [19], each diffraction pattern was recorded significantly longer due to photographic detection technique.

The quality of experimental data in this work was different in three series of measurements. The best (i.e. the lowest) value of the experimental $w R$-factor for $s M(s)$, showing the reproducibility of experimen- 


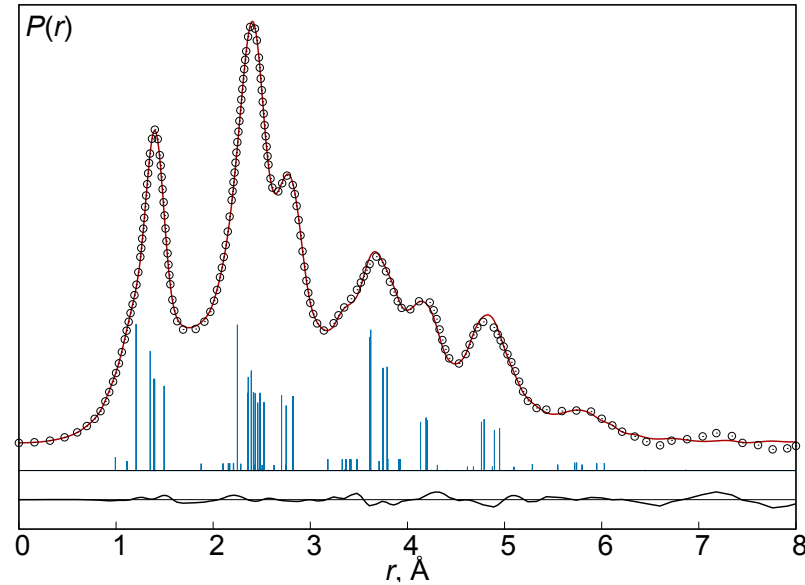

Figure 11: Experimental (circles) and model (line) radial distribution functions of benzoic acid. Below is the difference curve. Vertical bars indicate positions and contributions of all interatomic distances.

tal data, was in the experiment with benzoic acid. Accordingly, the very close value of the structural $w R$-factor of $2.52 \%$, showing the level of disagreement between the refined model and the experimental data, demonstrates an excellent fitting balance. In contrast, the data for $\mathrm{CHI}_{3}$ and $\mathrm{CI}_{4}$ were significantly noisier, especially for the latter molecule. Graphically this can be seen by comparing error bars in Figures 8, 9 and 10. This was expected, since iodine atoms generally lead to the very rapid dampening of diffraction patterns. The structural $w R$-factors were also expectedly larger, especially using very strict criteria for the smoothness of reduced background. If the background elimination procedure was applied to the total intensity functions of $\mathrm{CHI}_{3}$, the structural $w R$-factor was about $4 \%$. Nevertheless, in the real space the refined models are in very good agreement with the experimental data, as the radial distribution functions show in Figures 11, 12 and 13. Thus, the increased values of $w R_{\exp }$ and $w R_{\text {str }}$ were mostly due to random noise. Unfortunately, these statistics had not been well documented in the earlier investigations so no meaningful comparison could be done.

In Tables 2, 3 and 4 are collected most representative parameters of benzoic acid, iodoform and carbon

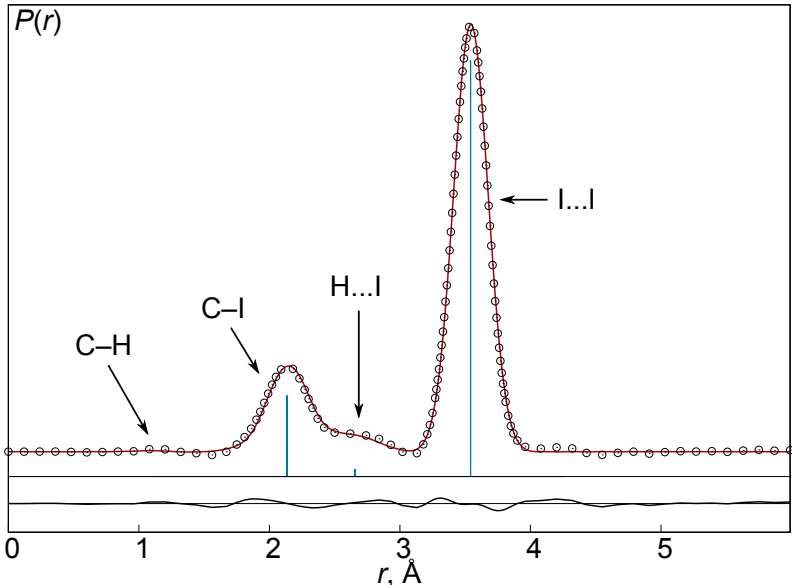

Figure 12: Experimental (circles) and model (line) radial distribution functions of iodoform. Below is the difference curve.

tetraiodide refined in this work in comparison to determined earlier experimental and theoretical values. The parameters for benzoic acid generally agree well with two exceptions. The length of the single $\mathrm{C}-\mathrm{O}$ bond is significantly smaller than theoretical value in this work, whereas in ref. [18] it is significantly larger. The length of the double $\mathrm{C}=\mathrm{O}$ bond seems to be accurate in our refinement and is clearly overestimated in the cited work.

In the refinement of iodoform $\mathrm{CHI}_{3}$ the bond length $r(\mathrm{C}-\mathrm{I})$ was strongly correlated with the angle $\angle(\mathrm{H}-$ C-I), since both of them determine equally well the distances in the strongest I . . I terms between iodine atoms. Therefore the $r(\mathrm{I} \cdots \mathrm{I})$ distance is the most representative parameter in iodoform if refined from electron diffraction data. The value determined in this work is in very good agreement with the best theoretical prediction if compared on the common basis of equilibrium geometry. With the older investigation we do comparison on the basis of vibrationally averaged $r_{\mathrm{g}}$ type of structure, which depends on the temperature of experiment. As expected, the value in our work is smaller than the published earlier. However, this difference of $0.008 \AA$ is larger than predicted $(0.003 \AA)$ taking into account the difference between temperatures of the experiments. On the 


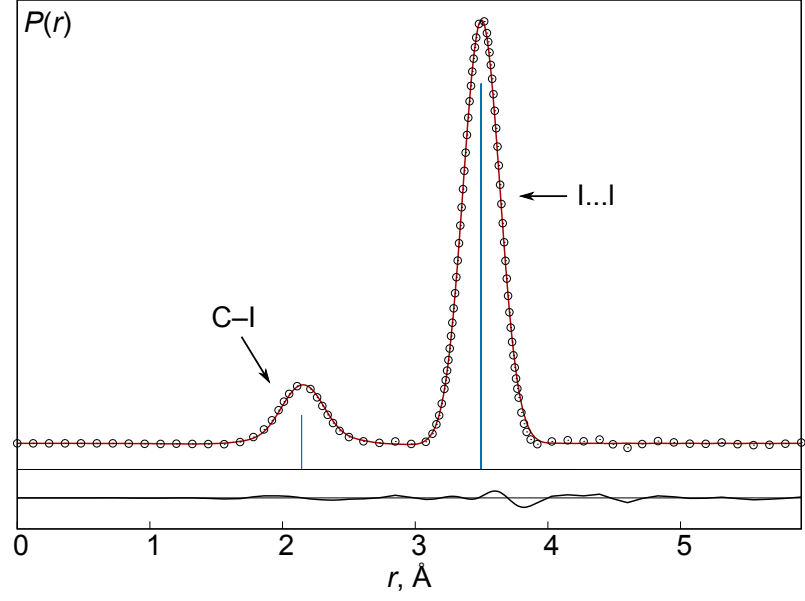

Figure 13: Experimental (circles) and model (line) radial distribution functions of carbon tetraiodide. Below is the difference curve.

other hand it is hardly possible to draw here a particular conclusion taking into account the relatively large uncertainty for this parameter. The reason for that was the ambiguity in the electron wavelength, which propagated into error limits of the refined parameters. This was due to the limited resolution of the IP scanner, which was used in this work. The length of the $\mathrm{C}-\mathrm{H}$ bond could not be refined at all due to the negligible contribution of this term into diffraction patterns, as the radial distribution functions show in Figure 12.

The most interesting results have been obtained for carbon tetraiodide. As has been already mentioned above in the introduction, the previous investigation was significantly hindered by the thermal decomposition [13]. As a result, a large amount of molecular iodine $\mathrm{I}_{2}$ (up to about $20 \%$ ) was formed together with other products. The iodine could be clearly seen on the experimental radial distribution function (see Figure 2 in the cited paper), which contained a signal at $c a . r=2.6 \AA$ characteristic for $\mathrm{I}_{2}$. This ended up considering several complicated models and relying on multiple assumptions in the interpretation of their data, which significantly increased ambiguity of results. In contrast, with LPGED this compound could be investigated at much lower temperature $(290 \mathrm{~K} v s$.
$396 \mathrm{~K}$ in ref. [13]) thus avoiding the thermal decomposition. The experimental radial distribution function in this work (Figure 13) shows only two distinct signals attributable to the $\mathrm{C}-\mathrm{I}$ and $\mathrm{I} \cdots \mathrm{I}$ terms of the tetrahedrally symmetric $\mathrm{CI}_{4}$ molecule. Its parameters are listed in Table 4. The interatomic distances refined from our data are smaller than theoretically predicted values. Although we calculated geometrical parameters extrapolated to the complete basis set, the influence of higher excitations in the coupled cluster method beyond $\operatorname{CCSD}(\mathrm{T})$ has not been investigated due to unfeasible computational demands. Therefore it is difficult to estimate the accuracy of the theoretical structure. The experimental values for $r_{\mathrm{g}}(\mathrm{C}-\mathrm{I})$ from this work and from the earlier investigation have an overlapping range within stated error limits. However, the values for $r_{\mathrm{g}}(\mathrm{I} \cdots \mathrm{I})$ are significantly different and cannot be explained by the temperature effect calculated to be about $0.003 \AA$. It is possible that the older value has been interfered with contributions from other products of decomposition containing I-C-I fragments. On the other hand our values also have increased error limits due to the contribution from the uncertainty in the electron wavelength.

Amplitudes of interatomic vibrations ( $l$ values in Tables 2, 3 and 4) have been also refined whenever possible. They were expectedly increased in comparison to theoretical values both in our as well as in the other investigations due to the effect of finite sample size $[44,45]$.

In this work the mean free path values were calculated for the three studied molecules from accurate kinetic diameters (see Table 1), which in turn were calculated from respective experimental viscosities [23]. In the case of unknown viscosity kinetic diameters can be calculated using quantum-chemical methods [46]. However, for the purposes of LPGED it is enough to estimate them by taking the maximal expected interatomic distance in the molecule multiplied by a factor of about 1.2-1.5. If the molecule has peripheral atoms with lone electron pairs the calculated value can be further increased by about 1-3 A. 


\section{Conclusions and Perspectives References}

In this paper we define the principles of low pressure gas electron diffraction (LPGED) and describe details on our implementation of this experimental method. With three test experiments using benzoic acid, iodoform and carbon tetraiodide we demonstrate the applicability of this method for measurements at significantly lower pressures and temperatures. For carbon teraiodide this was the only way to avoid sample decomposition under experimental conditions. Thus, the proposed method opens a possibility to study other thermally labile compounds. This can also be important in the case of conformationally flexible molecules, if only the most stable conformation must be investigated. In this work we have focused on experiments at low temperatures. Currently we are working on the extension of our setup for high temperature measurements, which are required for substances with low volatility. Another important direction of improvement is investigated by using detection techniques with higher resolution. This should further increase the accuracy and precision of the refined molecular parameters.

\section{Acknowledgments}

This work was supported by Deutsche Forschungsgemeinschaft (DFG, grant VI 713/1-2). YuVV is grateful to HPC facilities at the Universität zu Köln for providing computational time and programs. Many thanks to the mechanical workshop of the chemical faculty at the Bielefeld University, especially to Manfred Hoffmann and Jan-Ulrich Klamert. Special thanks to Norbert W. Mitzel for support and fruitful discussions.

\section{Keywords}

low pressure gas electron diffraction, experiment, molecular structure, benzoic acid, iodoform, carbon tetraiodide
[1] K. Hedberg et al. "Bond Lengths in Free Molecules of Buckminsterfullerene, $\mathrm{C}_{60}$, from Gas-Phase Electron Diffraction". In: Science 254.5030 (1991), pp. 410-412. DOI: $10.1126 /$ science. 254.5030 .410 .

[2] E. A. Seibold and L. E. Sutton. "Structure of Ferrocene". In: J. Chem. Phys. 23.10 (1955), pp. 1967-1967. DOI: 10.1063/1.1740629.

[3] G. V. Girichev et al. "Octamethylporphyrin copper, $\mathrm{C}_{28} \mathrm{H}_{28} \mathrm{~N}_{4} \mathrm{Cu}$ - A first experimental structure determination of porphyrins in gas phase". In: J. Mol. Struct. 978.1-3 (2010), pp. 163-169. DOI: 10.1016/j.molstruc. 2010. 02.029.

[4] J. Vogt and N. Vogt. "Structure searching in the MOGADOC database". In: J. Mol. Struct. 695696 (2004), pp. 237-241. DOI: doi:10.1016/j . molstruc. 2003.11.052.

[5] M. Hargittai and I. Hargittai. "Electron Diffraction Applications". In: Encyclopedia of Spectroscopy and Spectrometry. Ed. by J. C. Lindon. Second Edition. Oxford: Academic Press, 2010, pp. 456-460.

[6] I. Hargittai and M. Hargittai. "Electron Diffraction Theory and Methods". In: Encyclopedia of Spectroscopy and Spectrometry. Ed. by J. C. Lindon. Second Edition. Oxford: Academic Press, 2010, pp. 461-465.

[7] J. Tremmel and I. Hargittai. "Gas Electron Diffraction Experiment". In: Stereochemical Applications of Gas Phase Electron Diffraction, Part A: The Electron Diffraction Technique. Ed. by I. Hargittai and M. Hargittai. VCH Publishers, Inc., New York, 1988.

[8] R. J. F. Berger et al. "An Improved Gas Electron Diffractometer - The Instrument, Data Collection, Reduction and Structure Refinement Procedures". In: Z. Naturforsch. B 64b.11/12 (2009), pp. 1259-1268. 
[9] J. Tremmel and I. Hargittai. "Gas Electron Diffraction Part II. High-temperature Experimental Technique". In: Hung. Sci. Instrum. 50 (1980), pp. 43-49.

[10] S. L. Masters, G. V. Girichev, and S. A. Shlykov. "The re-determination of the molecular structure of antimony(III) oxide using very-high-temperature gas electron diffraction (VHT-GED)". In: Dalton Trans. 42.10 (2013), pp. 3581-3586. DOI: $10.1039 / \mathrm{c} 2 \mathrm{dt} 32790 \mathrm{~b}$.

[11] A. A. Ivanov et al. "A rebuilt electron diffractometer EG-100 for investigation of structures of low-volatile compounds (in Russian)". In: Prib. Tekh. Eksp. 2 (1974), pp. 270-272.

[12] N. P. Levkin et al. "High-temperature evaporators for electron diffractometer EG-100A (in Russian)". In: Prib. Tekh. Eksp. 6 (1967), pp. 130-133.

[13] M. Hargittai et al. "The Structure of Gaseous Carbon Tetraiodide from Electron Diffraction and All Carbon Iodides, $\mathrm{CI}_{\mathrm{n}}(\mathrm{n}=1-4)$, and Their Dimers, $\mathrm{C}_{2} \mathrm{I}_{2 \mathrm{n}}(\mathrm{n}=1-3)$ from HighLevel Computation. Any Other Carbon-Iodide Species in the Vapor?" In: Struct. Chem. 12.5 (2001), pp. 377-391. DOI: 10 . 1023 / a \% 3a1011960320787.

[14] A. A. Ivanov and E. Z. Zasorin. "Obtaining of electron diffraction patterns at low vapor pressures of investigated compound (in Russian)". In: Prib. Tekh. Eksp. 6 (1980), pp. 170-172.

[15] A. Ivanov. "Gas electron diffraction: the direction of development of the method". In: Mosc. Univ. Chem. Bull. 66.1 (2011), pp. 18-24. DOI: $10.3103 / \mathrm{s} 0027131411010044$.

[16] C. G. Reuter et al. "Gas electron diffraction of increased performance through optimization of nozzle, system design and digital control". In: Z. Naturforsch. B 71.1 (2016), pp. 1-13. DOI: 10.1515/znb-2015-0186.

[17] C. B. Lucas. Atomic and Molecular Beams, Production and Collimation. New York: CRC Press, 2014.
[18] K. Aarset, E. M. Page, and D. A. Rice. "Molecular Structures of Benzoic Acid and 2Hydroxybenzoic Acid, Obtained by Gas-Phase Electron Diffraction and Theoretical Calculations". In: J. Phys. Chem. A 110.28 (2006), pp. 9014-9019. DOI: 10.1021/jp0620825.

[19] H. Takeuchi et al. "Molecular structure of triiodomethane, $\mathrm{CHI}_{3}$, in the gas phase: an electron diffraction study". In: J. Mol. Struct. 657.1-3 (2003), pp. 381-384. DOI: 10 . $1016 /$ s0022-2860 (03) 00431-9.

[20] C. G. de Kruif and J. G. Blok. "The vapour pressure of benzoic acid". In: J. Chem. Thermodyn. 14.3 (1982), pp. 201-206. DOI: 10.1016/ 0021-9614 (82) 90011-8.

[21] I. Hazato and S. Seki. "The Vapour Pressures of Molecular Crystals. IV". In: J. Chem. Soc. Jpn. 64.4 (1943), pp. 475-482. DOI: 10.1246/ nikkashi1921.64.475.

[22] C. L. Yaws. The Yaws Handbook of Vapor Pressure: Antoine Coefficients. Gulf Professional Publishing, 2015. ISBN: 978-0-12-803002-8.

[23] Carl L. Yaws. Transport Properties of Chemicals and Hydrocarbons. Second edition. Elsevier, 2014. ISBN: 978-0-323-28658-9.

[24] Yu. V. Vishnevskii et al. "Molecular Structures of $o$ - and $m$-Fluoro(trifluoromethoxy)benzenes According to Gas Electron Diffraction and Quantum-Chemical Studies: Comparison of the Structures of Trifluoromethoxybenzene and Its Fluorinated Derivatives". In: Russ. J. Phys. Chem. 79.10 (2005), pp. 1537-1547.

[25] Yu. V. Vishnevskiy. "The Initial Processing of the Gas Electron Diffraction Data: an Improved Method for Obtaining Intensity Curves from Diffraction Patterns". In: J. Mol. Struct. 833 (2007), pp. 30-41. DOI: $10.1016 /$ j.molstruc. 2006.08 .026 .

[26] R. W. G Wyckoff. Crystal structures. 2nd. Vol. 1. New York: Interscience Publishers, 1963. 
[27] K. Raghavachari et al. "A fifth-order perturbation comparison of electron correlation theories". In: Chem. Phys. Lett. 157.6 (1989), pp. 479-483. DOI: 10 . 1016/s0009-2614 (89) 87395-6.

[28] K. A. Peterson and T. H. Dunning. "Accurate correlation consistent basis sets for molecular core-valence correlation effects: The second row atoms $\mathrm{Al}-\mathrm{Ar}$, and the first row atoms $\mathrm{B}-\mathrm{Ne}$ revisited". In: J. Chem. Phys. 117.23 (2002), pp. 10548-10560. DOI: 10.1063/1.1520138.

[29] Yu. V. Vishnevskiy et al. "Structure and Bonding Nature of the Strained Lewis Acid 3Methyl-1-boraadamantane: A Case Study Employing a New Data-Analysis Procedure in Gas Electron Diffraction". In: Chem. Eur. J. 18.34 (2012), pp. 10585-10594. DOI: 10.1002/chem. 201200264.

[30] A. D. Becke. "Density-functional thermochemistry. III. The role of exact exchange". In: $J$. Chem. Phys. 98.7 (1993), pp. 5648-5652. DOI: 10.1063/1.464913.

[31] P. J. Stephens et al. "Ab Initio Calculation of Vibrational Absorption and Circular Dichroism Spectra Using Density Functional Force Fields". In: J. Phys. Chem. 98.45 (1994), pp. 11623-11627. DOI: 10.1021/j100096a001.

[32] F. Weigend and R. Ahlrichs. "Balanced basis sets of split valence, triple zeta valence and quadruple zeta valence quality for $\mathrm{H}$ to $\mathrm{Rn}$ : Design and assessment of accuracy". In: $P C C P$ 7.18 (2005), pp. 3297-3305. DOI: 10 . $1039 /$ b508541a.

[33] K. A. Peterson et al. "On the Spectroscopic and Thermochemical Properties of $\mathrm{ClO}, \mathrm{BrO}$, IO, and Their Anions". In: J. Phys. Chem. A 110.51 (2006), pp. 13877-13883. DOI: 10.1021/ jp0658871.

[34] Chr. Møller and M. S. Plesset. "Note on an Approximation Treatment for Many-Electron Systems". In: Phys. Rev. 46.7 (1934), pp. 618-622. DOI: $10.1103 /$ physrev.46.618.
[35] J. M. L. Martin and A. Sundermann. "Correlation consistent valence basis sets for use with the Stuttgart-Dresden-Bonn relativistic effective core potentials: The atoms $\mathrm{Ga}-\mathrm{Kr}$ and In-Xe". In: J. Chem. Phys. 114.8 (2001), pp. 3408-3420. DOI: 10.1063/1.1337864.

[36] M. J. Frisch et al. Gaussian 16 Revision B.01. Gaussian Inc. Wallingford CT. 2016.

[37] J. F. Stanton et al. CFOUR, Coupled-Cluster techniques for Computational Chemistry, a quantum-chemical program package. With contributions from A.A. Auer, R.J. Bartlett, U. Benedikt, C. Berger, D.E. Bernholdt, Y.J. Bomble, O. Christiansen, F. Engel, R. Faber, M. Heckert, O. Heun, M. Hilgenberg, C. Huber, T.-C. Jagau, D. Jonsson, J. Jusélius, T. Kirsch, K. Klein, W.J. Lauderdale, F. Lipparini, T. Metzroth, L.A. Mück, D.P. O'Neill, D.R. Price, E. Prochnow, C. Puzzarini, K. Ruud, F. Schiffmann, W. Schwalbach, C. Simmons, S. Stopkowicz, A. Tajti, J. Vázquez, F. Wang, J.D. Watts and the integral packages MOLECULE (J. Almlöf and P.R. Taylor), PROPS (P.R. Taylor), ABACUS (T. Helgaker, H.J. Aa. Jensen, P. Jørgensen, and J. Olsen), and ECP routines by A. V. Mitin and C. van Wüllen. For the current version, see http://www.cfour.de.

[38] Yu. V. Vishnevskiy and Yu. A. Zhabanov. "New implementation of the first-order perturbation theory for calculation of interatomic vibrational amplitudes and corrections in gas electron diffraction". In: J. Phys.: Conf. Ser. 633.1 (2015), p. 012076.

[39] Yu. V. Vishnevskiy, 2020, UNEX version 1.6, http://unexprog.org (accessed April 16 2020).

[40] Yury V. Vishnevskiy, Sebastian Blomeyer, and Christian G. Reuter. "Gas standards in gas electron diffraction: accurate molecular structures of $\mathrm{CO}_{2}$ and $\mathrm{CCl}_{4}$ ". In: Struct. Chem. 31.2 (2020), pp. 667-677. DOI: 10 . $1007 /$ s11224019-01443-5. 
[41] Yu. V. Vishnevskiy et al. "Conformational and Bonding Properties of 3,3-Dimethyl- and 6,6-Dimethyl-1,5-diazabicyclo[3.1.0]hexane: A Case Study Employing the Monte Carlo Method in Gas Electron Diffraction". In: J. Phys. Chem. A 119.44 (2015), pp. 10871-10881. DOI: $10.1021 /$ acs . jpca. 5b08228.

[42] B. D. Hall et al. "An electron diffraction apparatus for small particle beams". In: Z. Phys. D 20.1 (1991), pp. 457-459. DOI: 10 . 1007 / bf 01544036 .

[43] L. S. Bartell, R. K. Heenan, and M. Nagashima. "Electron diffraction studies of supersonic jets. I. Apparatus and methods". In: J. Chem. Phys. 78.1 (1983), pp. 236-242. DOI: $10.1063 / 1$. 444546.

[44] I. L. Karle and J. Karle. "Internal Motion and Molecular Structure Studies by Electron Diffraction. III. Structure of $\mathrm{CH}_{2} \mathrm{CF}_{2}$ and $\mathrm{CF}_{2} \mathrm{CF}_{2}$ ". In: J. Chem. Phys. 18.7 (1950), pp. 963-971. DOI: 10.1063/1.1747820.

[45] R. B. Harvey, F. A. Keidel, and S. H. Bauer. "Some Effects of Nozzle Design on the Diffraction of Electrons by Gases". In: J. Appl. Phys. 21.9 (1950), pp. 860-874. DOI: $10.1063 / 1$. 1699775 .

[46] N. Mehio, S. Dai, and D. Jiang. "Quantum Mechanical Basis for Kinetic Diameters of Small Gaseous Molecules". In: J. Phys. Chem. A 118.6 (2014), pp. 1150-1154. DOI: $10.1021 /$ jp412588f. 


\title{
Low Pressure Gas Electron Diffraction: an Experimental Setup and Case Studies Supplementary Material
}

\author{
Yury V. Vishnevskiy, Sebastian Blomeyer, Christian G. Reuter
}

Table S1: Mean free path $l$ (in $\mathrm{mm}$ ) for molecules with different $d$ (in $\AA$ ) at selected temperatures $T$ (in $\mathrm{K})$ and pressures $P\left(\right.$ in mbar) ${ }^{\mathrm{a}}$

\begin{tabular}{|c|c|c|c|c|c|c|c|c|c|c|c|}
\hline$P$ & $T$ & $l$ & $P$ & $T$ & $l$ & $P$ & $T$ & $l$ & \multicolumn{3}{|c|}{$T$} \\
\hline \multicolumn{3}{|c|}{$d=5$} & \multicolumn{3}{|c|}{$d=10$} & \multicolumn{3}{|c|}{$d=15$} & \multicolumn{3}{|c|}{$d=20$} \\
\hline $10^{-4}$ & 300 & 373.9 & & 300 & 93.2 & & 300 & 41.4 & & 300 & 23.3 \\
\hline $10^{-3}$ & 300 & 37.3 & $10^{-3}$ & 300 & 9.3 & $10^{-3}$ & 300 & 4.1 & & 300 & 2.3 \\
\hline $10^{-2}$ & 300 & 3.7 & $10^{-2}$ & 300 & 0.9 & $10^{-2}$ & 300 & 0.4 & $10^{-2}$ & 300 & 0.2 \\
\hline $10^{-1}$ & 300 & 0.4 & $10^{-1}$ & 300 & 0.09 & $10^{-1}$ & 300 & 0.04 & $10^{-1}$ & 300 & 0.02 \\
\hline $10^{0}$ & 300 & 0.04 & $10^{0}$ & 300 & 0.01 & $10^{0}$ & 300 & 0.004 & $10^{0}$ & 300 & 0.002 \\
\hline $10^{-4}$ & 400 & 497.2 & & 400 & 124.3 & & 400 & 55.2 & & & 31.1 \\
\hline $10^{-}$ & 40 & .7 & & 40 & 2.4 & & 40 & 5.6 & & & 3.1 \\
\hline $10^{-2}$ & 400 & 5.0 & $10^{-2}$ & 400 & 1.2 & $10^{-2}$ & 400 & 0.6 & $10^{-2}$ & 400 & 0.3 \\
\hline $10^{-1}$ & 400 & 0.5 & $10^{-1}$ & 400 & 0.1 & $10^{-1}$ & 400 & 0.06 & $10^{-1}$ & 400 & 0.03 \\
\hline $10^{0}$ & 400 & 0.05 & $10^{0}$ & 400 & 0.01 & $10^{0}$ & 400 & 0.006 & $10^{0}$ & 400 & 0.003 \\
\hline & 500 & 1.5 & & & 5.4 & & 500 & 69.1 & & & 38.8 \\
\hline $10^{-3}$ & 500 & 62.2 & & 500 & 15.5 & $10^{-3}$ & 500 & 6.9 & & 500 & 3.9 \\
\hline $10^{-2}$ & 500 & 6.2 & & 500 & 1.6 & $10^{-2}$ & 500 & 0.7 & & 500 & 0.4 \\
\hline $10^{-1}$ & 500 & 0.6 & $10^{-1}$ & 50 & 0.2 & $10^{-1}$ & 500 & 0.07 & $10^{-1}$ & 500 & 0.04 \\
\hline $10^{0}$ & 500 & 0.06 & $10^{0}$ & 500 & 0.02 & $10^{0}$ & 500 & 0.007 & $10^{0}$ & 500 & 0.004 \\
\hline
\end{tabular}

a See paper for explanation of parameters and formula. 


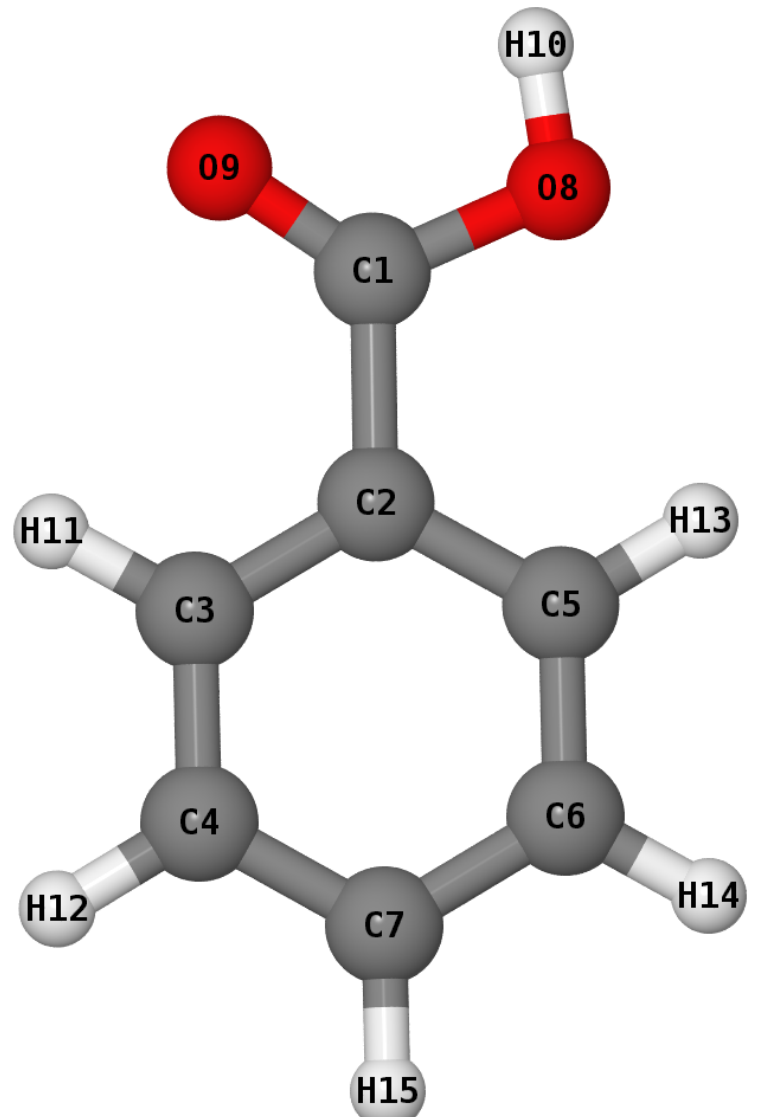

Figure S1: Molecular structure of benzoic acid with numeration of atoms.

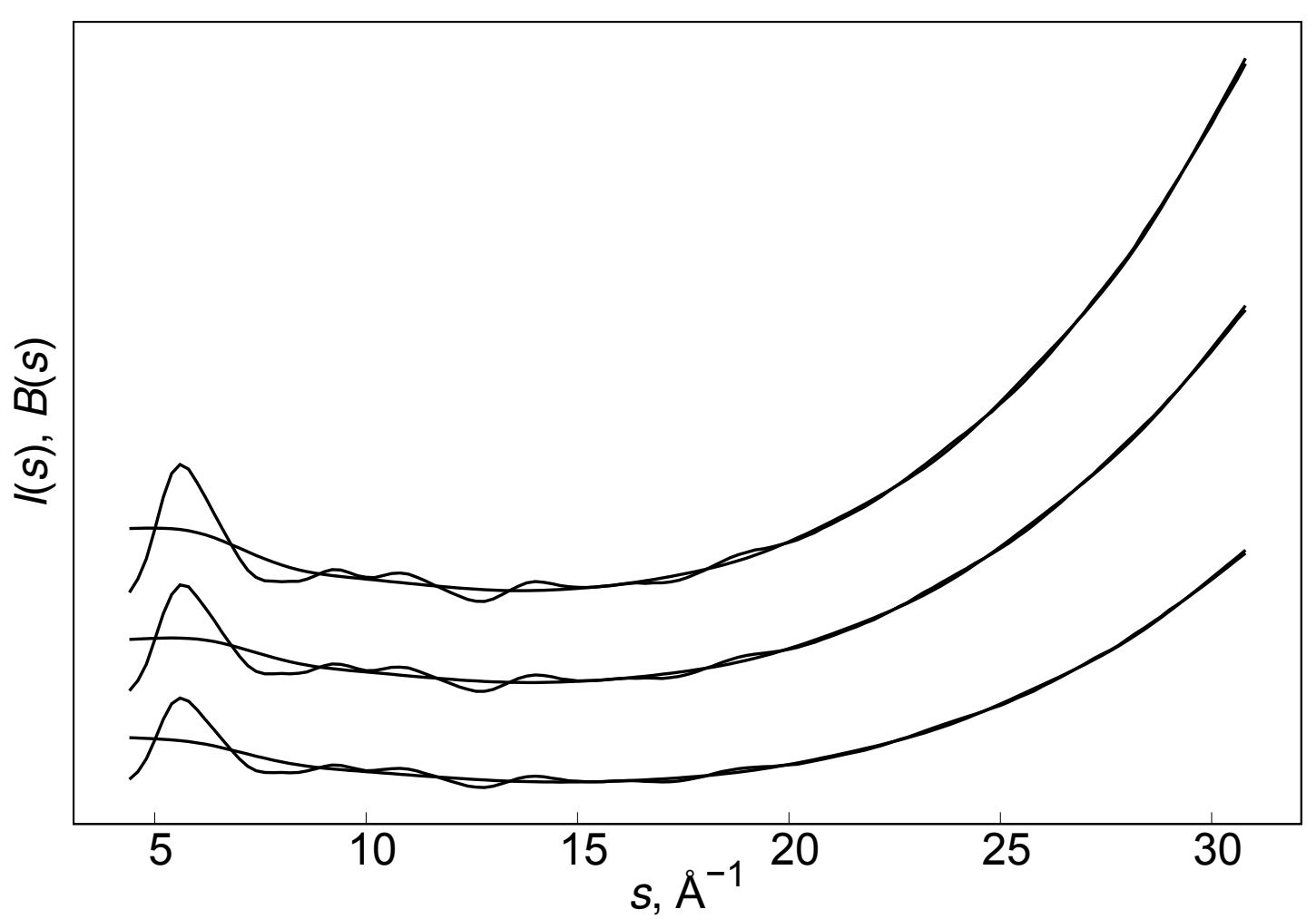

Figure S2: Reduced experimental intensity functions and background lines for benzoic acid. 


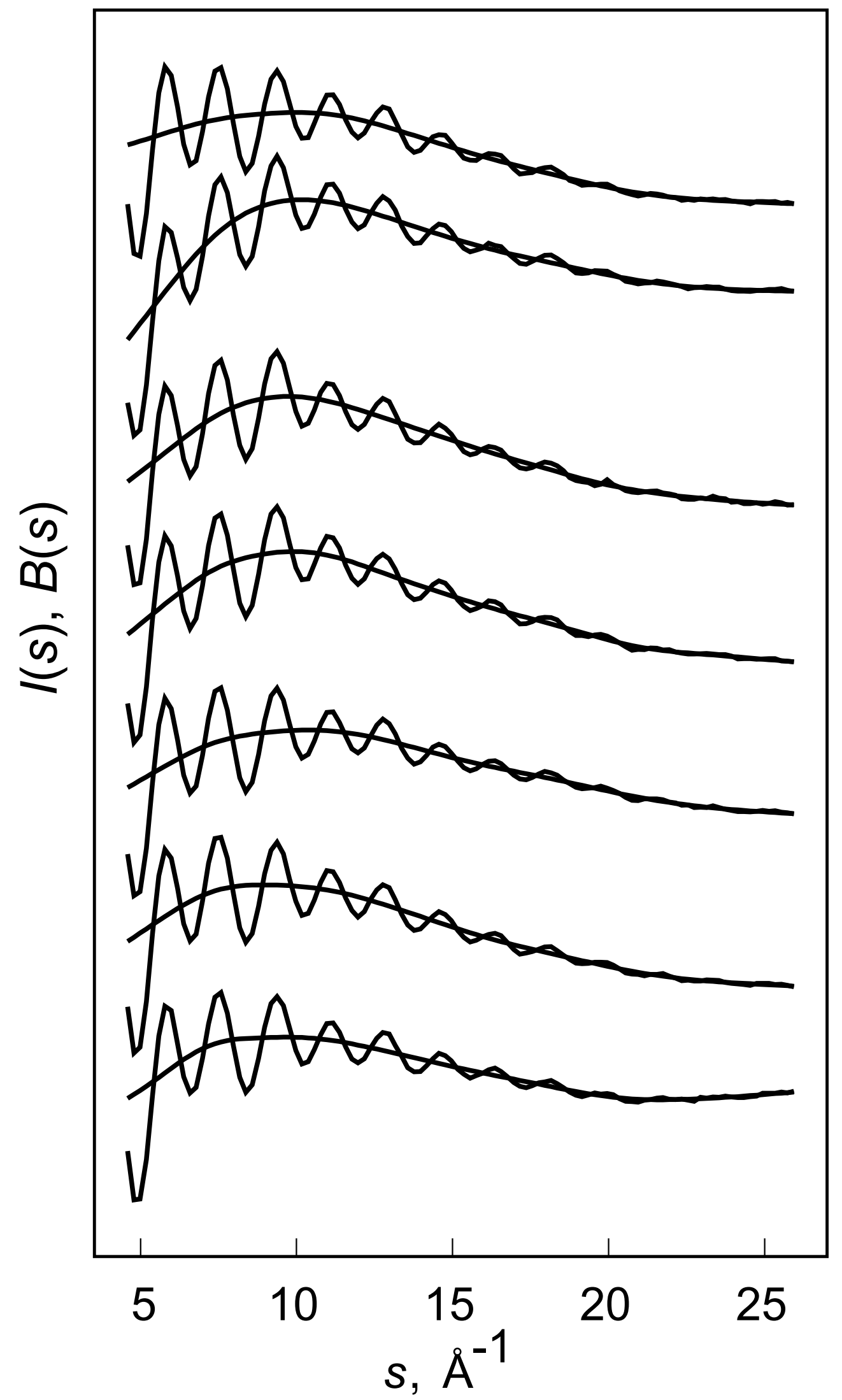

Figure S3: Reduced experimental intensity functions and background lines for iodoform. 


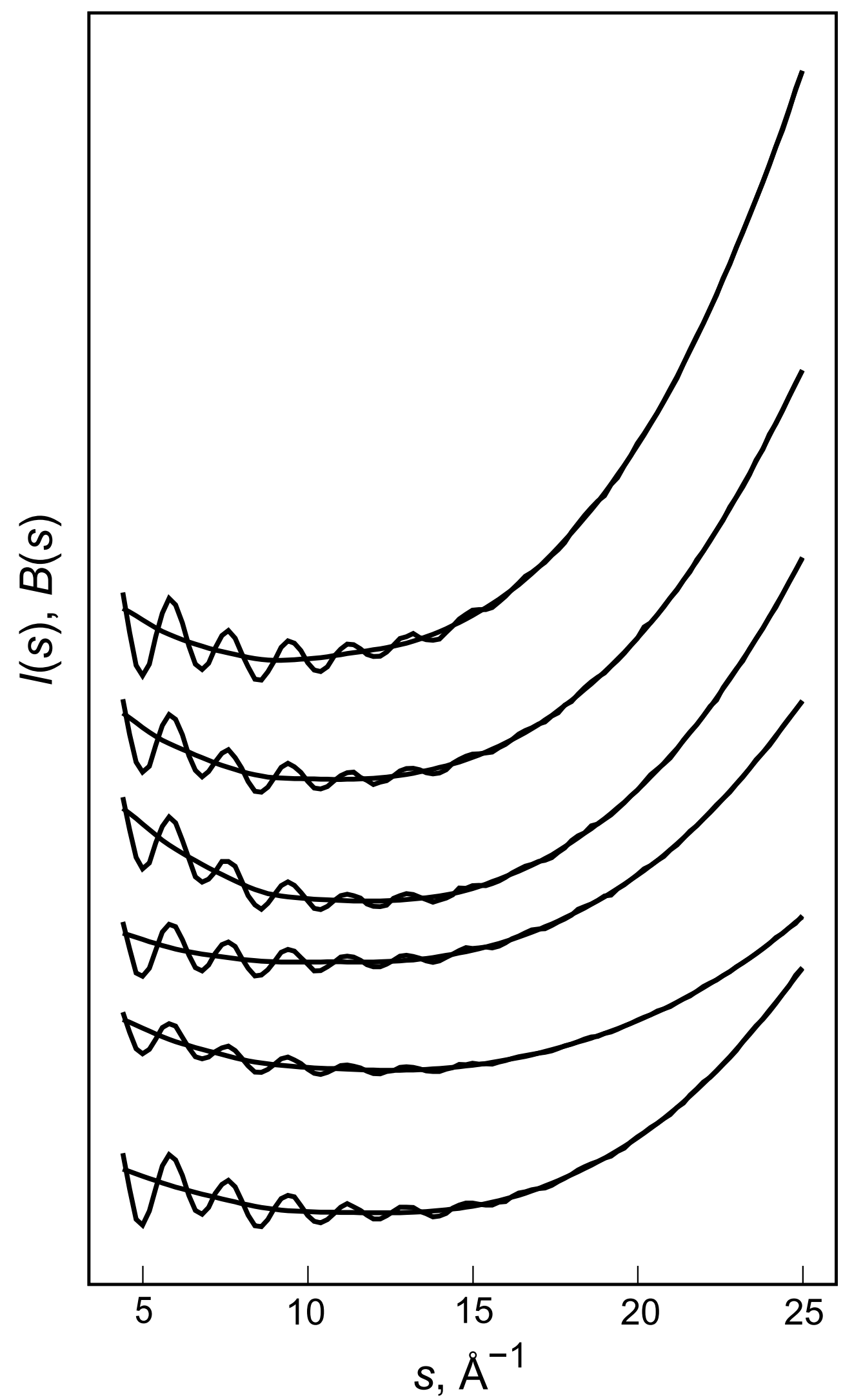

Figure S4: Reduced experimental intensity functions and background lines for carbon tetraiodide. 